\title{
Tests under irradiation of optical fibers and cables devoted to corium monitoring in case of severe accident in a Nuclear Power Plant
}

\author{
G. Cheymol*, L. Maurin, L. Remy, V. Arounassalame, H. Maskrot, S. Rougeault, V. Dauvois, \\ P. Le Tutour, N. Huot, Y. Ouerdane and P. Ferdinand \\ * Den - Service d'Etudes Analytiques et de Réactivité des Surfaces (SEARS), CEA, Université Paris-Saclay, \\ Gif-sur-Yvette, France \\ guy.cheymol@cea.fr
}

\begin{abstract}
The DISCOMS project, which stands for "DIstributed Sensing for COrium Monitoring and Safety", considers the potential of distributed sensing technologies, based on remote instrumentations and Optical Fiber Sensing cables embedded into the concrete floor under the reactor vessel, to monitor the status of this third barrier of confinement. This paper focuses on the selection and testing of singlemode (SM) optical fibers with limited RIA (Radiation Induced Attenuation) to be compliant with remote distributed instruments optical budgets, the ionizing radiation doses to sustain, and their reduction provided by the concrete basemat shielding. The tests aimed at exposing these fibers and the corresponding sensitive optical cables, to the irradiation doses expected during the normal operation of the reactor (up to 60 years for the European Pressurized Reactor), followed by a severe accident. Several gamma and mixed (neutron-gamma) irradiations were performed at CEA Saclay facilities: POSÉÏDON irradiator and ISIS reactor, up to a gamma cumulated dose of about 2 $M G y$ and fast neutron fluence ( $E>1 \mathrm{MeV})$ of $6 \times 10^{15} \mathrm{n} / \mathrm{cm}$. The first gamma test permitted to assess the RIA at various optical wavelengths, and to select three radiation tolerant singlemode fibers $(R I A<5 \mathrm{~dB} / 100 \mathrm{~m}$, at $1550 \mathrm{~nm}$ operating wavelength). The second one was performed on voluminous strands of sensitive cables encapsulating the selected optical fibers, up to approximately the same accumulated dose, at two temperatures: $30^{\circ} \mathrm{C}$ and $80^{\circ} \mathrm{C}$. A significant increase of the RIA, without any saturation tendency, appeared for fibers inserted into cables, correlated with the increase of the hydroxyl attenuation peak at $1380 \mathrm{~nm}$. Molecular hydrogen generated by the radiolysis of compounds of the cable is at the origin of this phenomenon. A third gamma irradiation run permitted to measure the radiolytic hydrogen
\end{abstract}

This project, with reference number ANR-11-RSNR-0007, was carried out within the framework of the RSNR (research on nuclear safety and radiation protection) research program launched after the Fukushima accident, co-funded by the French Programme d'Investissements d'Avenir and managed by the ANR (National Research Agency).

G. Cheymol, L. Remy, V. Arounassalame and H. Maskrot are with Den Service d'Études Analytiques et de Réactivité des Surfaces (SEARS), CEA, Université Paris-Saclay, F-91191, Gif-sur-Yvette, France (+33(0)1.69.08.62.71; e-mail: guy.cheymol@cea.fr)

L. Maurin and S. Rougeault are with Institut LIST, CEA, Université ParisSaclay, F-91120 Palaiseau, France. production yield of some compounds of a dedicated temperature cable sample. The efficiency of a carbon coating layer over the silica cladding, acting as a barrier against hydrogen diffusion, was also successfully confirmed. Finally, the efficiency of this carbon coating layer has also been tested under neutron irradiation, then qualified as a protection barrier against hydrogen diffusion in the optical fiber cores.

Index Terms - carbon coating layer, distributed measurement, hydrogen diffusion, gamma, neutron, optical fibers, rad-hard optical fiber, radiation effects, radiolysis.

\section{INTRODUCTION}

T $\mathrm{N}$ case of severe accident in a Nuclear Power Plant leading 1 to both reactor vessel failure and corium spreading, the loss of power supply can lead most of the instrumentations to be out of order with no way to monitor the status and the evolution of the accident.

After the Fukushima-Daiichi nuclear accident in March 2011, the so-called RSNR program -dedicated to nuclear security R\&D- has been launched in France to improve the mitigation solutions in case of severe accident for Gen II, Gen III (i.e. the EPR), and for future Gen IV nuclear reactors.

In this framework, the DISCOMS project aims at providing innovative solutions not requiring local electrical power supplies, for remote monitoring of such a severe nuclear accident [1].

One of the solutions investigated in the project [2] is based on distributed OFSs (Optical Fiber Sensors) to detect both the beginning of the severe accident, the corium pouring on the containment building concrete basemat, and its interaction with the concrete floor, until its spreads in the core catcher (in the

V. Dauvois and P. Le Tutour are with Den - Service du Comportement des Radionucléïdes (SECR), CEA, Université Paris-Saclay, F-91191, Gif-surYvette, France.

N. Huot was with Den - Service d'Exploitation du Réacteur OSiris (SEROS), CEA, Université Paris-Saclay, F-91191, Gif-sur-Yvette, France.

Y. Ouerdane is with Univ Lyon, UJM, CNRS, IOGS, laboratoire Hubert Curien, UMR 5516, 18 rue Prof. B. Lauras, 42000 Saint-Étienne, France

P. Ferdinand, previously with Institut LIST, is now with LMP S.A. 49-51 rue du Moulin des Prés, 75013 Paris, France. 
case of EPR). The OFSs cables are expected to be embedded into the concrete floor.

Since ionizing radiations affect the optical transmission properties of singlemode optical fibers, it appeared essential for this nuclear application to evaluate the level of attenuation induced on long term by these radiations.

This paper focuses on the tests conducted in order to expose selected fibers and the corresponding sensitive optical cables to irradiation doses expected during the normal operation of the reactor (up to 60 years for the European Pressurized Reactor), followed by a severe accident occurring at the end of this period which corresponds to the worst case of radiation dose to be sustained. It is important to notice that one task of the project was precisely to better assess these expected irradiation doses, the reactor being in normal operation [3] , and in case of severe accident [4].

Different gamma and mixed neutron/gamma irradiations have been conducted in lab facilities in the CEA research center based in Saclay: POSÉİDON irradiator and ISIS reactor, up to a gamma dose of about $2 \mathrm{MGy}$ and fast neutron fluence $(\mathrm{E}>1 \mathrm{MeV})$ of $6 \times 10^{15} \mathrm{n} / \mathrm{cm}$.

In the paper, we describe the selected fibers and cables, as well as the irradiation conditions for four irradiation tests. Then we present the RIA measurements and the corresponding analysis, including the measurements of the radiolytic hydrogen production yield of some compounds of the cable.

\section{OPTICAL FIBERS AND CABLES}

In our safety related project, even if optical fibers sensing cables are intended to be embedded into the reactor pit concrete basemat, and even if quite short lengths $(100 \mathrm{~m})$ are considered for corium monitoring, it is necessary to assess the RIA (Radiation Induced Attenuation) levels and to select the less sensitive fibers to be compliant with the radiation doses to be sustained and the measurement systems optical budgets, in the frame of 60 years of normal operation of the NPP, followed by a severe accident.

The behavior of fibers under ionizing radiations, especially $\gamma$ rays, has been widely studied during the last decades, highlighting the various parameters which influence the RIA levels and kinetics, see [5] for a recent review. The measurement wavelength, which is a critical parameter, is somehow imposed by the available optical technologies [6]: $1550 \mathrm{~nm}$ being the dominating telecom wavelength, for both singlemode fibers and distributed sensing instruments.

The tested SingleMode Fibers (SMFs) are typically $9 \mu \mathrm{m}$ core diameter, and $125 \mu \mathrm{m}$ optical cladding diameter, surrounded by a protective coating made of polymer or even metal, leading to an outside fiber diameter typically ranging from $155 \mu \mathrm{m}$ to $250 \mu \mathrm{m}$. In general, optical fiber behavior under ionizing radiations mainly depends on the fiber core composition, where the light waves propagate mainly. From previous research, pure-silica and fluorine-doped cores (both with F-doped cladding) are the most radiation-hardened optical fibers in the domain of dose aimed, up to $100 \mathrm{kGy} / 1 \mathrm{MGy}$ for steady state irradiation $[5,7,8]$.

Selection of OFSs is an output of the project. So, three different rad-hard optical fibers, named "a", "b" and "c", have been tested under irradiation, as well as a standard Corning SMF28 fiber (non rad-hard).

Due to the relatively short sensing lengths intended to be used inside the reactor building in such an application (typ. $<100 \mathrm{~m}$ per cable), we stated that the maximum acceptable RIA shall be less than $5 \mathrm{~dB}$ at $1550 \mathrm{~nm}$ for $100 \mathrm{~m}$, i.e. $50 \mathrm{~dB} / \mathrm{km}$, with regards to the typical optical budgets of todays distributed measurements systems.

After a first $\gamma$ irradiation test with a batch of standalone optical fibers, the best 3 rad-hard fibers fulfilling these requirements have all been selected, in order to be embedded in 3 different types of sensing cables (distributed temperature and strain measurements cables, plus safety cables) [6] for complementary irradiation tests to evaluate any additional cable influence on the RIA. The irradiation tests were mainly focused on long length temperature sensing cables (a few $\mathrm{mm}$ diameters), requiring high volume irradiators.

Last, a fourth rad-hard fiber, named "d", incorporating a thin layer of carbon between the cladding and the coating, has also been irradiated.

Table 1 sums up the general characteristics of the five fibers tested, and mentions which ones have been inserted in a sensing temperature cable. Cable with the fiber "a" inside will be named "Ca", cable with the fiber "b" inside will be named " $\mathrm{Cb} ", \ldots$ As far as possible, for clarity, all graphs related to fiber "a" or cable " $\mathrm{Ca}$ " are colored in green, the corresponding color is blue for fiber " $b$ " or cable " $\mathrm{Cb}$ ", the corresponding color is red for fiber "c" or cable "Cc", and black is associated with SMF28 fiber and fiber "d" or cable "Cd".

TABLE 1.

GENERAL CHARACTERISTICS OF TESTED FIBERS AND CABLES

\begin{tabular}{ccc}
\hline \hline Fiber & Type of fiber & Associated Cable \\
\hline $\mathrm{a}$ & rad-hard & $\mathrm{Ca}$ \\
$\mathrm{b}$ & rad-hard & $\mathrm{Cb}$ \\
$\mathrm{c}$ & rad-hard & $\mathrm{Cc}$ \\
$\mathrm{d}$ & rad-hard with carbon coating & $\mathrm{Cd}$ \\
SMF28 & Standard & \\
\hline \hline
\end{tabular}

\section{IRRADIATIONS - EXPERIMENTAL TEST PROCEDURE}

The irradiations performed in the project aims at testing fibers and cables in a configuration which is similar to the aimed environment, or rather in a configuration able to produce the same effects on fibers. We first consider a radiation level at the basemat surface in a very conservative configuration, since the reactor concrete basemat will act as a radiation protection and will drastically decrease the cumulated doses to be sustained $v s$. optical cable embedment depth.

\section{A. Irradiation level to withstand}

Two different phases have to be simulated: an operational phase (nominal operation lasting up to 60 years) and an accident phase with corium spreading out of the reactor vessel. Modeling has shown that the doses are of the same order of magnitude for the operational and for the accidental phases, although the dose rates be quite different: in the range of $\mathrm{Gy} / \mathrm{h}$ for the first, and $20 \mathrm{kGy} / \mathrm{h}$ for the second. The RIA depends on the level of cumulative irradiation dose, but also generally on 
the dose rate and the complete history in terms of succession of the different dose rates undergone by the optical fibers, the latter being quite complex. In other terms, that is the expected cumulative dose which is first considered below.

On the basis of the information available at the beginning of the project, the nominal configuration -representative of the irradiation level at the top of the concrete basemat, below the reactor vessel- aims to simulate $250 \mathrm{kGy}$ for the operational phase, and at least $450 \mathrm{kGy}$ during the first $24 \mathrm{~h}$ of the accident.

Nevertheless, our fine modeling of the $\gamma$ dose at the surface of the concrete and assessments made, considering both the operational phase [3] and the first $24 \mathrm{~h}$ of the accident, lead us to consider slightly higher values: about 1 to a few MGy. It has also been assessed that the operational phase may produce a fast neutrons fluence $(\mathrm{E}>1 \mathrm{MeV})$ up to $10^{15} \mathrm{n} / \mathrm{cm}$ or more on the basemat top surface, leading us to consider an irradiation in the vicinity of the nuclear reactor core.

The dose reduction $v s$. the embedment depth has also been considered, it depends on several parameters (concrete type, corium composition...). The evaluation resulted in a reduction of one order of magnitude after the first $40 \mathrm{~cm}$ in the concrete floor for both Gen II and Gen III, based on the fact that in the reactor pit, the main damage is the result of 60 years of irradiation during normal operation [3].

\section{B. Irradiation facilities}

$\gamma$ irradiations have been carried out in the POSÉİDON industrial pool type irradiator of the Applied Radiation Laboratory (LABRA) [9] in Saclay. In the associated casemate, 2 source planes produce about $10,000 \mathrm{TBq}(300,000 \mathrm{Ci})$, for a maximum dose rate of $6 \mathrm{kGy} / \mathrm{h}$, homogeneous $( \pm 10 \%)$ between the source planes in a volume of approximate dimensions: $1 \mathrm{~m} \times 0.6 \mathrm{~m} \times 0.4 \mathrm{~m}$ (Fig. 1). The irradiation runs were performed at room temperature (RT), $20^{\circ} \mathrm{C}$ to $30^{\circ} \mathrm{C}$ or at $80^{\circ} \mathrm{C}$ by using an adapted oven in place in the irradiator casemate.

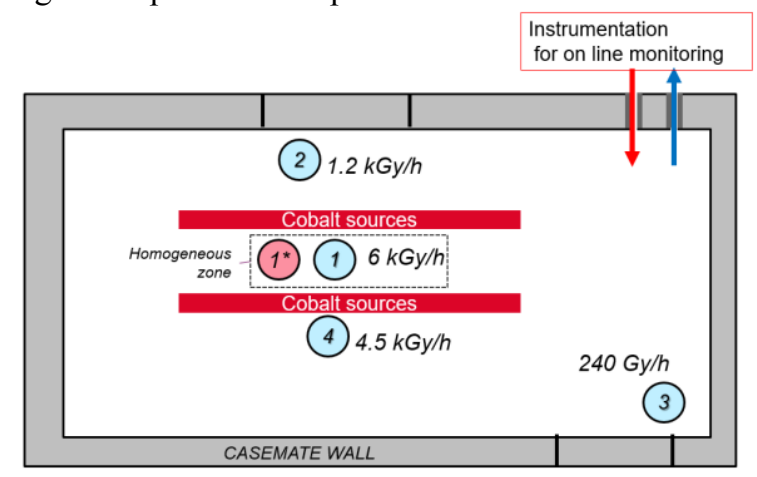

Fig. 1. Diagram of the POSÉIIDON casemate with positions used, and associated dose rate. $1 *$ simply differs from 1 by a higher temperature (about $80^{\circ} \mathrm{C}$ instead of room temperature).

Neutron irradiation were carried out in the ISIS research reactor [10] (installation which is now shut down), mainly dedicated to education and training, with a nominal power of $640 \mathrm{~kW}$. Samples of optical fibers were placed in the vicinity of the reactor core in small capsules. Fast neutrons $(\mathrm{E}>1 \mathrm{MeV})$ flux was $2.8 \times 10^{11} \mathrm{n} / \mathrm{cm} / \mathrm{s}$. Thermal neutrons flux was $2.4 \times 10^{12} \mathrm{n} / \mathrm{cm} / \mathrm{s}$, superposed with an associated $50 \mathrm{kGy} / \mathrm{h} \gamma$ dose rate. The temperature during the irradiation was about $40^{\circ} \mathrm{C}$.

\section{Four successive irradiation tests}

1) Irradiation 1: $\gamma$ irradiation of $100 \mathrm{~m}$ long fibers

The $100 \mathrm{~m}$ long fibers were wound on a $15 \mathrm{~cm}$ diameter strand and connected thanks to a feedthrough to an instrumentation placed outside the casemate for online monitoring. The optical fibers were tested in 4 configurations, with different dose rates or temperatures. In the nominal configuration, fibers were first in position (2) (see Fig. 1) during $215 \mathrm{~h}$, then moved in position (1) for the next $113 \mathrm{~h}$ (this configuration being named "(2) to (1)"), for a total fluence 5 times lower that tested with the configuration "(3) to (2)".

The maximum fluence achieved during the irradiation test was performed by leaving fibers all the time in the position (1), or $(1)$, which also permitted to assess the influence of increased temperature.

Table 2 gives the temperature, dose rate, cumulated dose for each phase of the irradiation 1 , for the 4 configurations.

TABLE 2

IRRADIATION 1: $\gamma$ IRRADIATION OF FIBERS, DOSE AND DOSE RATE IN 4 CONFIGURATIONS

\begin{tabular}{|c|c|c|c|c|}
\hline Config. & Temp. & $\begin{array}{c}\text { Operational } \\
\text { Phase }(215 \mathrm{~h}) \text { : } \\
\text { dose } \\
\text { dose rate }\end{array}$ & $\begin{array}{c}\text { Accident } \\
(113 \mathrm{~h}): \\
\text { dose } \\
\text { dose rate }\end{array}$ & $\begin{array}{c}\text { Total } \\
(328 \mathrm{~h}): \\
\text { cumulated } \\
\text { dose }\end{array}$ \\
\hline \multirow[t]{2}{*}{ (2) to (1) } & $20^{\circ} \mathrm{C}$ & $250 \mathrm{kGy}$ & $650 \mathrm{kGy}$ & $900 \mathrm{kGy}$ \\
\hline & & $1.2 \mathrm{kGy} / \mathrm{h}$ & $5.7 \mathrm{kG} / \mathrm{h}$ & \\
\hline \multirow[t]{2}{*}{ (3) to (2) } & $20^{\circ} \mathrm{C}$ & $49 \mathrm{kGy}$ & $131 \mathrm{kGy}$ & $180 \mathrm{kGy}$ \\
\hline & & $230 \mathrm{kG} / \mathrm{h}$ & $1.2 \mathrm{kG} / \mathrm{h}$ & \\
\hline \multirow[t]{2}{*}{ (1) } & $20^{\circ} \mathrm{C}$ & $1.2 \mathrm{MGy}$ & $700 \mathrm{kGy}$ & $1.9 \mathrm{MGy}$ \\
\hline & & $5.7 \mathrm{kG} / \mathrm{h}$ & $5.7 \mathrm{kG} / \mathrm{h}$ & \\
\hline \multirow[t]{2}{*}{ (1) } & $80^{\circ} \mathrm{C}$ & $1.2 \mathrm{MGy}$ & $700 \mathrm{kGy}$ & $1.9 \mathrm{MGy}$ \\
\hline & & $5.7 \mathrm{kGy} / \mathrm{h}$ & $5.7 \mathrm{kGy} / \mathrm{h}$ & \\
\hline
\end{tabular}

2) Irradiation 2: $\gamma$ irradiation of $100 \mathrm{~m}$ long optical cables

Optical sensing cables "Ca", "Cb" and "Cc" equipped with rad-hard selected optical fibers have been irradiated. This time, the $100 \mathrm{~m}$ long cables give a much more voluminous strand, typically $40 \mathrm{~cm}$ diameter with a section of $5 \mathrm{~cm}$ or greater. Hopefully, the POSEÏDON irradiator is well adapted to this run since it presents a relatively large irradiation zone with a homogeneous dose rate.

Here again, the cables were connected to remote distributed instrumentation outside the casemate for online monitoring. We kept the coiled cables in the same position during the $303 \mathrm{~h}$ irradiation time, with a dose rate of $5 \mathrm{kGy} / \mathrm{h}$, resulting in a cumulated dose of $1.5 \mathrm{MGy}$.

It is mainly the positions $(1)$ and $(1)$ that have been tested. One cable was in the position (2), with a dose rate of $1.05 \mathrm{kGy} / \mathrm{h}$ resulting in a $320 \mathrm{kGy}$ cumulated dose.

\section{3) Irradiation 3: $\gamma$ irradiation of short length of optical fibers and cable}

Short lengths of optical fibers and cables, and bulbs with various components of the temperature cable, have been irradiated in the position (4), but in this case without any online measurement. The dose rate: $4.5 \mathrm{kGy} / \mathrm{h}$ during $400 \mathrm{~h}$, lead to 
about 1.8 MGy cumulated dose.

4) Irradiation 4: Neutrons $+\gamma$ irradiation of short optical fiber lengths

Shorts lengths of optical fibers have been irradiated in the vicinity of the ISIS reactor core, without online measurement. The fibers were wound in several strands of diameter ranging from $3 \mathrm{~cm}$ to $4 \mathrm{~cm}$.

The power of the reactor was set to $640 \mathrm{~kW}$, the irradiation lasted 6 hours. Dose rate and cumulated dose are displayed on Table 3 .

TABLE 3

TEST 4: $\mathrm{N}+\gamma$ IRRADIATION OF OPTICAL FIBERS

\begin{tabular}{ccc}
\hline \hline & DOSE RATE & DOSE \\
\hline Fast neutrons & $2.8 \times 10^{11} \mathrm{n} / \mathrm{cm} / \mathrm{s}$ & $6 \times 10^{15} \mathrm{n} / \mathrm{cm}$ \\
Thermal neutrons & $2.4 \times 10^{12} \mathrm{n} / \mathrm{cm} / \mathrm{s}$ & $5.2 \times 10^{16} \mathrm{n} / \mathrm{cm}$ \\
$\gamma$ & $50 \mathrm{kGy} / \mathrm{h}$ & $300 \mathrm{kGy}$ \\
\hline \hline
\end{tabular}

Even if the $1550 \mathrm{~nm}$ nominal wavelength was especially considered, it was also interesting to assess the RIA on a larger spectral range. On that purpose, the beams of 2 SLED centred at $1550 \mathrm{~nm}$ and $1310 \mathrm{~nm}$ and a large spectrum halogen source were combined with optical couplers. In order to avoid any photobleaching, as far as possible, the total power injected in the fibers was in the range of $1 \mu \mathrm{W}$.

\section{RESULTS AND ANALYSIS OF TEST $1: \gamma$ IRRADIATION OF THE RAD-HARD SINGLEMODE OPTICAL FIBERS}

The various configurations have been described in section III with a summary in Table 2.

For all optical fibers considered, the RIA increases during the irradiation, faster when the dose rate is higher, as shown on graph related to configuration (2) to (1) (Fig. 2).

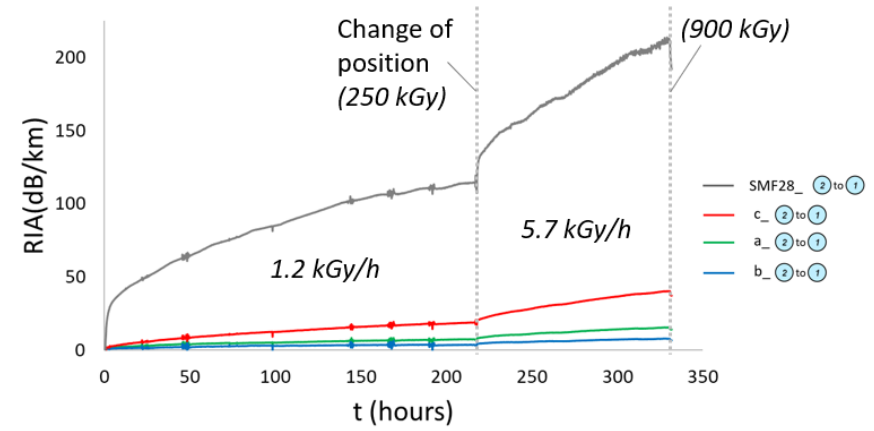

Fig.2.RIA@1550nm vs. time for fibers $a, b, c$ and SMF 28 during irradiation 1/configuration "(2) to(1)". The dose rate is $1.2 \mathrm{kGy/h}$ before the change of position and $5.7 \mathrm{kGy} / \mathrm{h}$ after. At the change of position, the cumulated dose is $250 k G y$, at the end of irradiation, it reaches $900 k G y$.

Fig. 3 shows the difference in RIA for one rad-hard fiber when it is irradiated at either $22^{\circ} \mathrm{C}$ or $80^{\circ} \mathrm{C}$. The RIA decreases when the temperature increases, as already reported, e.g. in reference [11].

This first test confirmed that some rad-hard optical fibers have much less RIA than standard commercial Ge-doped fiber, in the range of $50 \mathrm{~dB} / \mathrm{km}$ or less (down to $10 \mathrm{~dB} / \mathrm{km}$ ), at $1550 \mathrm{~nm}$ with a cumulated dose of $1 \mathrm{MGy}$ or greater.

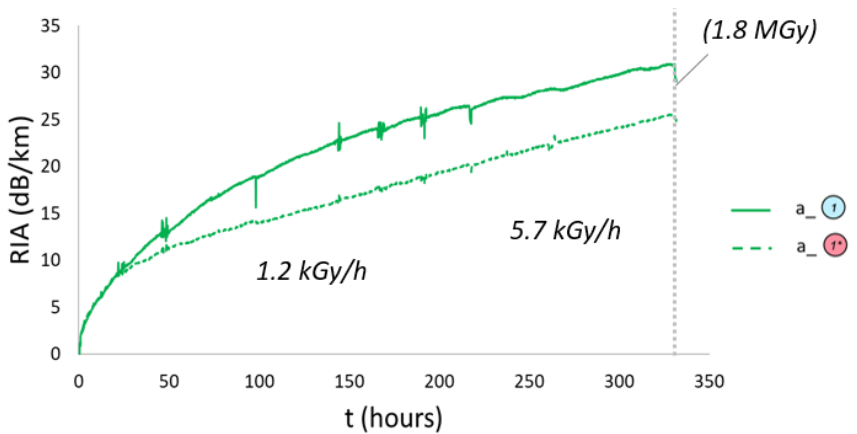

Fig. 3. RIA@1550nm vs. time for fiber a during irradiation 1 in configuration (1) $\left(22^{\circ} \mathrm{C}\right)$ and $\left(10\left(80^{\circ} \mathrm{C}\right)\right.$. The dose rate is $5.7 \mathrm{kGy}$ and the cumulated dose is $1.8 \mathrm{MGy}$ at the end of irradiation.

\section{RESULTS AND ANALYSIS OF TEST 2: $\gamma$ IRRADIATION OF OPTICAL SENSING CABLES}

The selected rad-hard optical fibers have been inserted in sensing cables and irradiated in the POSÉİDON irradiator. We focus below on the tests of the temperature sensing cables in configurations (1) and (1) (Fig. 1). For comparison, we also irradiated the same fibers, conditioned in the same way (not into cable, but standalone), like the previous test based on configuration (1).

The RIA of the optical fibers inserted into cables happened to be higher than for the same standalone fibers, as shown on Fig. 4 for fiber a, without any tendency to saturation.

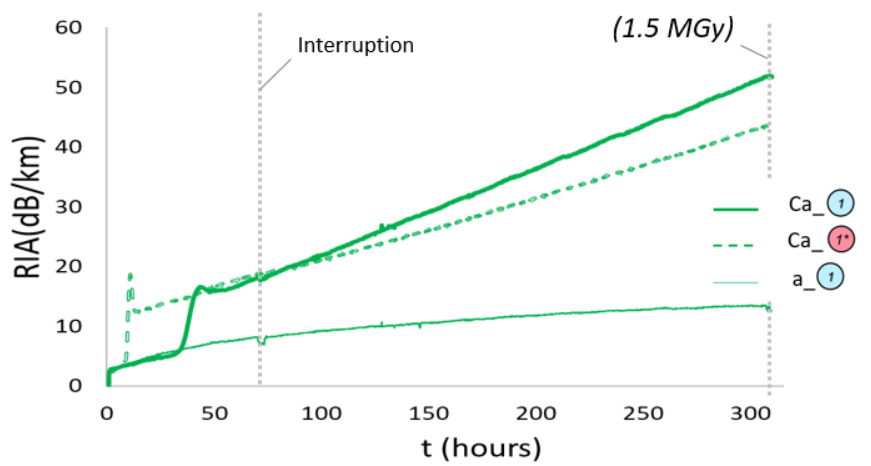

Fig. 4. Irradiation 2: RIA@1550nm vs. time for fiber a in position (1) (see Fig. 1), at room temperature (RT), and cables Ca, at RT (position (1) and in oven at $80^{\circ} \mathrm{C}$ (position (10). The dose rate is about $5 \mathrm{kGy} / \mathrm{h}$. At the end of irradiation, the cumulated dose is about 1.5 MGy.

The graphs of RIA spectrum on a large spectrum range permitted to better understand the reason for the difference between RIA in standalone fibers with those inserted in cables. The increase of the RIA at $1550 \mathrm{~nm}$ is due to the large attenuation peak centred at $1380 \mathrm{~nm}$ (Fig. 5), which reveals the presence of hydroxyl groups in the fiber core.

Such peak is likely to be generated by the production of hydrogen by radiolysis of polymer components of cables; the hydrogen then diffuses towards the fiber core and induces the creation of hydroxyl groups. 


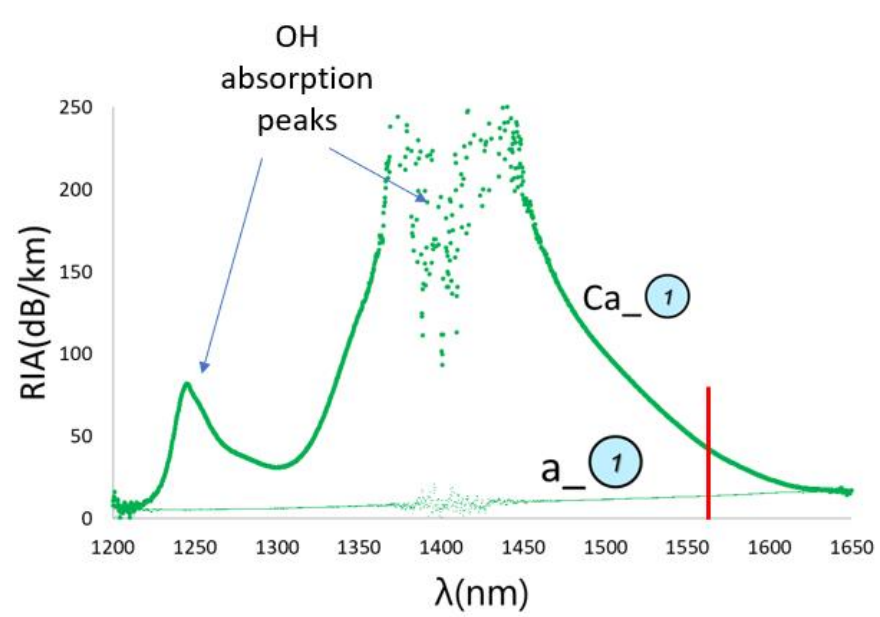

Fig. 5. RIA spectrum for fiber $a$ and cable Ca at the end of irradiation 2 (cumulated dose: $1.5 \mathrm{MGy})$, in position (1) $\left(30^{\circ} \mathrm{C} / 5 \mathrm{kGy} / \mathrm{h}\right)$.

\section{RESULTS AND ANALYSIS OF TEST 3: $\gamma$ IRRADIATION OF CABLES AND CARBON COATED OPTICAL FIBER PARTS}

Even if the RIA observed with fiber into cables remains acceptable for this project, mainly because the embedment in the concrete will drastically decrease the dose received by the fibers, avoiding or reducing the amount of hydrogen diffusing towards the fiber core, it remains of scientific interest. In that objective, we have tested a cable equipped with a carbon coated fiber. Such a thin carbon layer is known to protect the silicabased fibers from external hydrogen which, without it, could diffuse towards the core and induce additional attenuation [12].

The tested cable incorporating this fiber was not made according to standard manufacturing procedure: the original optical fiber was replaced off-line in the temperature cable by a rad-hard carbon coated fiber "d", thus giving cable "Cd" (see Table 1). Then, $3.4 \mathrm{~m}$ of this cable $\mathrm{Cd}$ was irradiated, as well as the same lengths of cables $\mathrm{Ca}, \mathrm{Cb}$, and $\mathrm{Cc}$ placed in the position (4) within the irradiator POSÉÏDON (see Fig. 1), at the dose rate $4.5 \mathrm{kGy} / \mathrm{h}$ during 401 hours, leading to a cumulated dose of 1.8 MGy. Again, there was no on-line monitoring. The focus on the $\mathrm{OH}$ peak, with potentially high RIA, permitted to accommodate with the short fiber lengths tested.

Following the irradiation phase, the attenuation ${ }^{1}$ of fibers inserted into cables was measured thanks to a strongly attenuated Supercontinuum source, and the same ANRITSUTM OSA as used in previous experiments. Corresponding graphs are depicted on Fig. 6, showing the absence of any $\mathrm{OH}$ peak for the carbon coated fiber irradiated into the cable, which demonstrates the efficiency of such carbon layer for the intended purpose.

To support the study of induced attenuations, some measurements were also carried out on specific components of the temperature sensing cable, in order to study the formation of volatile compounds, and in particular $\mathrm{H} 2$ dihydrogen, during the irradiation 3 .

\footnotetext{
${ }^{1}$ We may notice this is not a classical RIA measurement, since there is no online monitoring. The lack of repeatability in the loss of optical fiber connections prevents to make reliable measurements of the attenuation. We
}

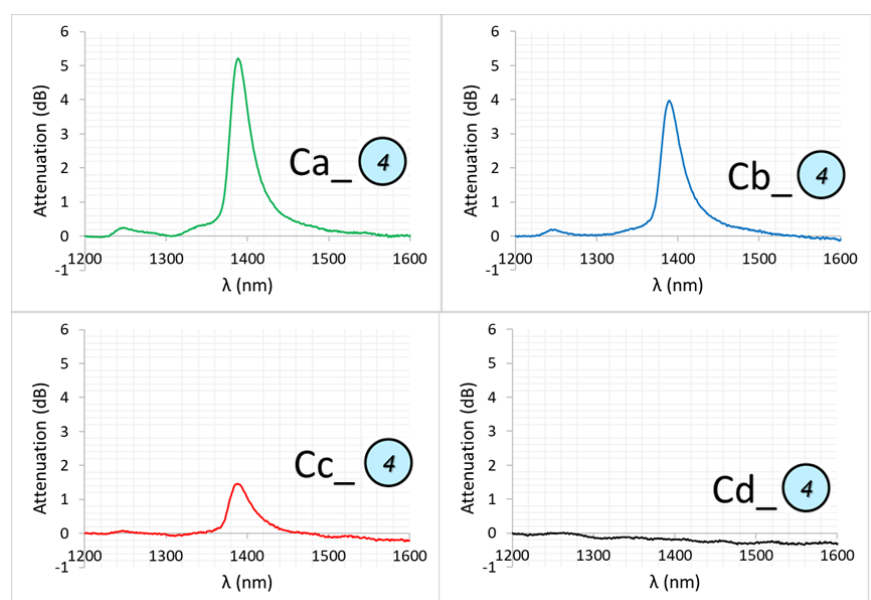

Fig. 6. Attenuation vs. $\lambda$ for fibers into cables $\mathrm{Ca}, \mathrm{Cb}, \mathrm{Cc}, \mathrm{Cd}$ after irradiation 3; cables in position (4) $\left(22^{\circ} \mathrm{C} ; 4.5 \mathrm{kGy} / \mathrm{h} ; 1.8 \mathrm{MGy}\right)$. To erase the attenuation due to connectors, all graphs are normalised to cancel attenuation at $1200 \mathrm{~nm}$, where RIA is expected to be very low on such short lengths.

These materials have been irradiated into sealed glass bulbs. Extra components were also tested, including two kinds of gel surrounding the optical fiber used in temperature sensing cables. Such gels are used as a conductive thermal layer to improve thermal efficiency, but have also a tendency to induce some significant friction, which is a matter of concern when the measuring technique is sensitive to both strain and temperature, especially when only the latter information is wanted. Also, a piece of the overall cable, made mainly of one surrounding polymer material, was tested. For each material, 2 bulbs of about $20 \mathrm{~cm}^{3}$ were used with reconstituted air (with krypton as tracer). Two bulbs with only reconstituted air have been added for reference.

At the end of the irradiation, the gaseous mixture in each ampoule was analysed by direct injection mass spectrometry and magnetic sector, to obtain both characterization and quantification of all species. The formation of hydrogen, expressed in number of moles per unit length of fiber, or cable, is recorded in Table 4.

TABLE 4

PRODUCTION OF HYDROGEN FOR 1.8 MGy

\begin{tabular}{ccc}
\hline \hline Component & Bulb \# & $\begin{array}{c}\text { Hydrogen produced } \\
\left(\mathrm{mol}_{\mathrm{H}} / \mathrm{m}\right)\end{array}$ \\
\hline Coated fiber & 1 & $8.6 \times 10^{-7}$ \\
& 2 & $9.8 \times 10^{-7}$ \\
Gel 1 & 3 & $6.6 \times 10^{-4}$ \\
& 4 & $7.2 \times 10^{-4}$ \\
Gel 2 & 5 & $5.5 \times 10^{-4}$ \\
& 6 & $5.6 \times 10^{-4}$ \\
Overall cable & 7 & $4.2 \times 10^{-3}$ \\
& 8 & $5.4 \times 10^{-3}$ \\
\hline \hline
\end{tabular}

The overall optical cable and its surrounding polymer material produce the major part of hydrogen while irradiated.

have normalised all graphs to get equivalent zero attenuation at $1200 \mathrm{~nm}$, where RIA is expected to be very low for such short fiber lengths. 
Dividing this production by the mass of each component permit to calculate the radiolytic hydrogen production yield. This time, the higher value is coming from the gels, with a yield of about $210^{-7} \mathrm{~mol} / \mathrm{J}$ for about $1.8 \mathrm{MGy}$.

It does not come from this study that a specific element of the cable is mainly responsible for the production of hydrogen, and can be removed or substituted by another more favourable element with respect to this application.

\section{VII. $\mathrm{N}+\gamma$ IRRADIATION OF SHORT FIBER LENGTHS AND CONCLUSION}

Finally, the efficiency of the carbon coating layer has also been tested under neutron irradiation, showing its good efficiency as a protection barrier against hydrogen diffusion in the core of silica optical fibers.

Thanks to different tests conducted, we have been able to recommend the better rad-hard optical fiber for the aimed application, compliant with 60 years of normal operation of the NPP followed by a severe accident, and compliant with an installation respectively at minimum $30 \mathrm{~cm}$ and $5 \mathrm{~cm}$ below the surface of the concrete basemat for Gen II and Gen III reactors.

An optical fiber with carbon coating layer should therefore be systematically preferred for such application, or/and either any other means to protect the core of the fiber from the diffusion of hydrogen and its effects on attenuation. However, the long-term efficiency of the carbon coating under ionizing radiations should be further investigated.

\section{REFERENCES}

[1] P. Ferdinand et al., "Optical Fiber Sensors to improve the safety of Nuclear Power Plants," Asia Pacific Optical Sensors, APOS2013, Wuhan, China, $17^{\text {th }}-21^{\text {st }}$ Oct. 2013.

[2] P. Ferdinand et al, "DISCOMS: DIstributed Sensing for COrium Monitoring and Safety," CANSMART, Vancouver, BC, Canada, 15-17 July 2015. https://hal-cea.archives-ouvertes.fr/cea$\underline{02151741}$

[3] M. Brovchenko et al., "Neutron-gamma flux and dose calculations for feasibility study of DISCOMS instrumentation in case of severe accident in a GEN 3 reactor." EPJ Web of Conferences 153 , 07030 (2017) - ICRS-13 \& RPSD-2016. 25 Sept. 2017. https://doi.org/10.1051/epjconf/201715307030.

[4] TRIPOLI-4 Project Team, "TRIPOLI-4 v8 User Guide", CEA-R-6316 (Feb. 2013). www.oecdnea.org/tools/abstract/detail/nea-1716/.

[5] S. Girard, A. Morana, A. Ladaci, T. Robin, L. Mescia, J.J. Bonnefois, M. Boutillier, J. Mekki, A. Paveau, B. Cadier, E. Marin, Y. Ouerdane, and A. Boukenter, "Recent advances in radiation-hardened fiber-based technologies for space applications", Journal of Optics, vol 20, no. 9, Aug. 2018, Art. no. 093001.

[6] L. Maurin et al., "Remote monitoring of Molten Core-Concrete Interaction experiment with Optical Fibre Sensors \& perspectives for severe nuclear accident monitoring - DISCOMS project," $6^{\text {th }}$ international conference on Advancements in Nuclear Instrumentation Measurement Methods and their Applications, ANIMMA 2019, 17-21 June 2019, Portorož, Slovenia.

[7] T. Wijnands, L. K. De Jonge, J. Kuhnhenn, S. K. Hoeffgen, and U. Weinand, "Optical absorption in commercial single mode optical fibers in a high energy physics radiation field," IEEE Trans. Nucl. Sci., vol. 55, no. 4, pp. 2216-2222, Aug. 2008.

[8] X. Phéron, S. Girard, A. Boukenter, B. Brichard, S. Delepine-Lesoille, J. Bertrand, and Y. Ouerdane, "High -ray dose radiation effects on the performances of Brillouin scattering based optical fiber sensors," Opt. Exp., vol. 20, pp. 26978-26985, 2012.

[9] http://www-centre-saclay.cea.fr/fr/Le-Labra-une-plateforme-d-irradiationau-service-des-industriels-et-des-chercheurs
[10] F. Foulon, B. Lescop, and X. Lohleber, "Development of education and training programs using ISIS research reactor". Joint IGORR 2013 \& IAEA Technology Meeting, Korea, 13-18 Oct 2013.

[11] J. Kuhnhenn, S. K. Hoffgen, and U. Weinand, "Quality Assurance for Irradiation Tests of Optical Fibers: Uncertainty and Reproducibility", IEEE Trans. Nucl. Science, vol. 56, no. 4, pp.2160-2166, August 2009.

[12] A. Mendez and T. F. Morse, "Specialty Optical Fibers Handbook"; https://www.elsevier.com/books/specialty-optical-fibershandbook/mendez/978-0-12-369406-5 